\title{
Modal epistemology, modal concepts, and the Integration Challenge
}

\begin{abstract}
The paper argues against Peacocke's moderate rationalism in modality. In the first part, I show, by identifying an argumentative gap in its epistemology, that Peacocke's account has not met the Integration Challenge. I then argue that we should modify the account's metaphysics of modal concepts in order to avoid implausible consequences with regards to their possession conditions. This modification generates no extra explanatory gap. Yet, once the minimal modification that avoids those implausible consequences is made, the resulting account cannot support Peacocke's moderate rationalism.
\end{abstract}

\section{Introduction}

Modal epistemology has flourished. A lot has been written since van Inwagen wrote (1998) that "Modal epistemology is a subject about which little is known" (75). One way to motivate the question that modal epistemologists are trying to answer is by analogy to Benacerraf's dilemma for mathematics. ${ }^{1}$ Let us assume modal mindindependence. $^{2}$ If we assume further that we have modal knowledge, the challenge arises as to how we are able to obtain knowledge of the extra-mental modal realm. For our senses give us access to what is actually the case, but it is not clear that they give us access to what is merely possible, necessary, or impossible. This challenge has traditionally been presented in the literature as involving the need for a necessitysensitive faculty that would enable us to recognize modal facts, followed by the claim that we cannot make sense of such a faculty. ${ }^{3}$ The idea behind the alleged need for this faculty is the so-called 'causal account of knowledge', which would require all knowledge to be fundamentally grounded in causal affection. (Benacerraf 1973, 661).

One might dislike this way of motivating the challenge. However, the idea of a potential need for this faculty is still dominant in the literature, to the extent that some - most notably the rationalists - are explicitly interested in denying that we need it (e.g., (Peacocke 1999, 189)) while others are explicitly interested in naturalizing it, thereby reducing its mysteriousness (e.g., (Williamson 2007), (Kment 2006)).

Vaidya (2007) has classified accounts of modal knowledge in three main groups. There are counterfactual-based accounts (e.g., (Hill 2006), (Williamson 2007)), according to which modal epistemology is a special case of the epistemology of counterfactuals. There are conceivability-based accounts (e.g., (Yablo 1993), (Menzies 1998), (Chalmers 2002)), according to which modal knowledge is somehow

\footnotetext{
${ }^{1}$ See (Benacerraf 1973).

${ }^{2}$ For a stimulating discussion about different notions of mind-independence, see (Jenkins 2005).

${ }^{3}$ See (Blackburn 1986) and (Craig 1985) for two such formulations.
} 
inferred from conceivability knowledge with the aid of a thesis that would appropriately link $p$ 's conceivability and $p$ 's possibility. And there are understandingbased accounts (e.g., (Bealer 1999, 2002), (Peacocke 1999 and 2002)), according to which possession of concepts and understanding of contents is the main source of modal knowledge. ${ }^{4}$

Counterfactual- and conceivability-based accounts have received most attention in the recent years, and one can find in the literature several criticisms against them. ${ }^{5}$ While those criticisms are not decisive, the initial unreflective enthusiasm for these kinds of accounts is no longer in good health. This decrease in optimism makes the exploration of alternative approaches a somehow urgent task.

One such alternative - the target of this paper - is Peacocke's understandingbased account which, despite its numerous attractive features, has not received due attention. Something that the epistemologies mentioned hitherto have in common is the presupposition that modal truth is mind-independent. What makes Peacocke's account especially interesting is that it is specifically designed with a view to meeting the epistemic challenge in a way that is appropriate to the account's mind-independent and metaphysical commitments. It is, therefore, specifically designed to meet what Peacocke calls 'the Integration Challenge'; a problem of reconciliation (Peacocke 1999, p.1).

It is worth noting that the plausibility of the account's metaphysics is not parasitic upon the plausibility of the account's epistemology. This is good news in relation to the aim of this paper. I shall argue below that Peacocke's epistemology of modality is unsatisfactory, but I am sympathetic to the account's metaphysics of modality. Nothing developed in the course of my criticisms against Peacocke's epistemology suggests that the metaphysics of modality of the account is also in need of revision. On the contrary, Peacocke's metaphysics of modality-a kind of linguistic ersatzism - is one of the most sophisticated and elaborated ones, and possibly one of the strongest versions of linguistic ersatzism that have been developed after Lewis' objections (1986) to this variety of ersatzism. In addition, and unlike Lewis' genuine realism, a metaphysics along the lines of Peacocke's can easily accommodate impossible worlds without additional ontological extravagance, ${ }^{6}$ and this is also good news in a context in which impossible worlds are increasingly called for. $^{7}$

As far as the epistemology of modality is concerned, most of the task of this paper is negative. I argue that an epistemology along the lines of Peacocke's is not

\footnotetext{
${ }^{4}$ One should not understand this taxonomy as exclusive, though. For instance, Williamson's epistemology of modality is both a counterfactual-based account and a conceivability-based account.

5 Against counterfactual-based accounts, see (Vaidya 2007), (Jenkins 2008a) and (Roca-Royes, forthcomingb). Against conceivability-based account, see (Worley 2003), (Brueckner 2001), (Lowe 2007), (Wright 2002a) and (Roca-Royes, forthcominga).

${ }^{6}$ I couldn't explain why this is so better than Nolan does in (1997, 541-2).

${ }^{7}$ See (Nolan 1997, 536-541) for a survey of their applications.
} 
satisfactory. For reasons I have developed elsewhere, ${ }^{8}$ I also think that conceivabilityand counterfactual-based accounts are not in a good position either. Yet, I believe that we possess modal knowledge, and that this calls for an epistemology of modality. There is, therefore, a lot to be done in terms of developing a positive account. To the reader's dissatisfaction, however, this task falls beyond the scope of the present paper.

As indicated above, Peacocke's metaphysics of modality will not be discussed here. I will take issue, however, with Peacocke's metaphysics of modal concepts. Peacocke believes that modal concepts are very rich in content. So rich that they imply possession conditions that might well be found implausible on their own. I find it objectionable too that the content that Peacocke endows modal concepts with seems to have been chosen with the Integration Challenge in mind. It is, suspiciously, the minimum amount of content required for the implementation of Peacocke's moderate rationalism. If I am right that his epistemology is unsuccessful for independent reasons, nothing would be lost if we endorsed a thinner view on modal concepts. Again, a thinner view on the metaphysics of modal concepts is still compatible with the account's metaphysics of modality, so nothing developed here will go against it either. Something to be highlighted, however, is that, to avoid implausible commitments regarding the possession conditions for modal concepts, modal concepts will need to be thin to an extent that will make Peacocke's moderate rationalism unworkable.

The paper is structured as follows. In $\S 2$, I briefly present the key elements of Peacocke's account (and provide source pages when appropriate). In $\S 3$, I argue that the account's epistemology is unsatisfactory and reply to an anticipated objection to my criticisms. In $\S 4$, I briefly anticipate the dialectical impact of $\S 5$ in relation to $\S 3$. In $\S 5$, I offer reasons against Peacocke's metaphysics of modal concepts and suggest my amendment, which will result in an account incapable of supporting Peacocke's moderate rationalism. Last section (§6) recapitulates and offers some remarks about the prospects of the resulting, modified account favoured here.

\section{Meeting the Integration Challenge: Moderate Rationalism}

As stated above, the Integration Challenge is the challenge of reconciling the metaphysics and the epistemology of a given domain. The way Peacocke thinks this reconciliation should be achieved in modality is by means of a moderately rationalist strategy. Moderate rationalism "seeks to explain cases of a priori knowledge by appeal to the nature of the concepts that feature in contents that are known a priori" (Peacocke 2004, 199). In this section, and avoiding any unnecessary detail, I will first survey Peacocke's metaphysics of modality to then focus on his integrated epistemology.

\footnotetext{
${ }^{8}$ (Roca-Royes, forthcominga) and (Roca-Royes, forthcomingb).
} 
At the metaphysical level, Peacocke identifies possible worlds with sets of thoughts and propositions, determined by a set of Principles of Possibility. Let us see how he gets there.

An assignment, $s$, is a 4-tuple $<D_{s}, v a l_{s}$, propval $_{s}$, ext $>$ where $D_{s}$ is its associated domain; $v a l_{s}$ is a function from concepts to extensions; propval is a function from atomic concepts to properties and relations; and $e x t_{s}$ is a function from properties and relations to extensions. Only those assignments that satisfy all Principles of Possibility are admissible. For any assignment, $s$, the set of thoughts and propositions that $s$ counts as true is called 's-specification'. The set of possible worlds is identified with the set of those specifications that correspond to admissible assignments. The concept $<$ possibility>, therefore, applies to specifications (and correctly so only to some of them: the possible worlds). By contrast, <admissibility $>$ applies to assignments (and correctly so only to those who do not violate any Principle of Possibility).

The (first-order) Principles of Possibility divide into the Modal Extension Principle (MEP), and a battery of Constitutive Principles. The main idea underlying MEP is that any concept is governed by a certain rule, $R$, whose application determines, in each case, the actual extension of the concept:

Modal Extension Principle. An assignment $s$ is admissible only if: for any concept $C$, the semantic value of $C$ according to $s$ is the result of applying the same rule as is applied in the determination of the actual semantic value of C. (Peacocke 1999, 136)

MEP rules, at the level of concepts, what the Constitutive Principles rule at the level of reference: namely, that admissible assignments respect constitutive relations. Peacocke provides a couple of examples of plausible Constitutive Principles. The first one here concerns the fundamental kind of an object:

If $\mathrm{P}$ is a property which is an object $x$ 's fundamental kind, then an assignment is inadmissible if it counts the proposition $x$ is $P$ as false. (Peacocke 1999, 145)

Under the assumption that it is constitutive of a person $a$ that she originates in the particular sperm $b$ and egg cell $c$ from which she actually originated, the following is also a constitutive principle (for $a$ ):

An assignment is inadmissible if it both counts the proposition a exists as true and counts the proposition a develops from $b$ and $c$ as false. (Peacocke 1999, 146)

The first-order principles provide necessary conditions for an assignment to be admissible. A second-order principle, Constrained Recombination, states that they are jointly sufficient. These are the principles, therefore, that fix "a rule for determining the actual extension of the concept admissible." (Peacocke 1999, 151)

The Integration Challenge is met by letting the Principles of Possibility play two roles in the account. First, they determine the set of possible worlds - this is the 
metaphysical role just sketched. Second, they constitute the possession conditions for the concept <possibility>, and our implicit knowledge of them is thereby guiding our modal judgements. Let us see how the combination of these two roles would make the account meet the Integration Challenge. The Principles of Possibility encode constitutive (essential) truths, and should be conceived of as the axioms (or metaphysical laws) to be satisfied for an arbitrary set of thoughts and propositions to be counted as a genuine possibility. Where $C^{*}$ is the set of all assignments, the metaphysical role of the principles is to divide $C^{*}$ into two: the set of admissible ones, and the complementary set of inadmissible ones. In turn, these principles are constitutive of the concept < possibility>, meaning by this that one does not possess the concept unless one has implicit knowledge of them. This, combined with the first, metaphysical role, implies that, merely in virtue of possessing the concept $<$ possibility >, one has implicit access to (which) possible worlds (there are). Possible worlds are the truth-makers for modal claims. Consequently, possession of $<$ possibility $>$ gives us epistemic access to modal truth. Our modal beliefs, therefore, can safely be given the epistemic status of knowledge:

If it is granted that implicit knowledge of the Principles of Possibility is appropriately employed in reaching modal judgement, we can see how the judgement so reached is knowledge. Provided that any non-modal principles upon which she relies are known, a thinker's modal judgements reached by the proper use of the implicit knowledge of the Principles of Possibility will, in the nature of the case, be knowledge. This is not only a matter of reliability. The judgement of the modal truth is explained by the thinker's implicit grasp of principles which make the modal truth hold. (Peacocke 1999, 162)

The account avoids commitment to a necessity-sensitive faculty because modal knowledge is achieved, according to moderate rationalism, by (implicit) reasoning from the Principles of Possibility, thereby avoiding the need for "causal interaction with a modal realm" (Peacocke 2004, 222).

In sum, modal knowledge is analysed as consequential upon our implicit knowledge of the Principles of Possibility, such that the epistemic status of our modal beliefs is inherited from the epistemic status of the Principles of Possibility. The (fairly uncontroversial) assumption here is that known premises-Principles of Possibility — and valid reasoning lead to known conclusions-Modal Knowledge.

This is a good first step towards meeting the challenge. Especially when, blocking a potential charge of circularity, and appealing to Kit Fine's views on the notion of essence, Peacocke takes the Principles of Possibility to be non-modal. According to (Fine 1994), constitutive - i.e., essential — facts are ontologically prior to modal ones. Modal truth is, in Fine's approach, ontologically consequential upon constitutive truth. This ontological analysis is used by Peacocke to defend the noncircularity of his parallel epistemological analysis, according to which modal knowledge is consequential upon constitutive knowledge. 


\section{The Revenge of the Integration Challenge.}

If Peacocke were to leave things there, however, one could complain that, rather than solving the challenge, he has only moved it from the domain of explicit modal knowledge to the domain of implicit knowledge about the constitutive. As he puts it:

The provision of a general theory of the constitutive, as opposed to the modal, seems to me to be an urgent task for philosophy. We certainly do not want all the initial puzzlement about modality simply to be transferred to the domain of the constitutive. Only a satisfactory general theory of the constitutive, and an attendant epistemology, can allay this concern. (Peacocke 1999, 166 fn.)

This worry is justified; and pressing. Peacocke's claim that modal beliefs reached by reasoning constitute modal knowledge presupposes that we know the Principles of Possibility. Our knowledge that a necessarily originates from $o$, for instance, is grounded, on his account, in our implicit knowledge of the Principles of Possibility, which somehow include knowledge that a essentially originates from $o$. It would be objectionable to say - and I dare to speculate that this is why Peacocke doesn't say it - that, since constitutive knowledge is not modal knowledge, the challenge for modal knowledge has been met. First, Fine's ontological divorce between the modal and the constitutive does not amount to a divorce in epistemological worries. On the contrary, after the divorce, the same challenge should be phrased in terms of both modal and constitutive knowledge. Second, it seems generally true that, when we know about $\varphi$ because we infer it from $\Psi$, the knowability conditions for $\varphi$-facts are not fully elucidated unless the knowability conditions for $\Psi$-facts are. This is what Peacocke is laudably acknowledging in the above quotation.

We should then enquire about the nature of constitutive facts so that we know, broadly, the kind of constitutive epistemology we should be aiming at. We know that modal truth is ontologically consequential from constitutive truth and that the former is mind-independent for Peacocke. So should be the latter, therefore. Consequently, we should aim at an epistemology of mind-independent constitutive facts. We can call this 'the revenge of the integration challenge' because, as Peacocke suspects, the success of his epistemology of modality depends on the success of his (or an) epistemology of the constitutive. Furthermore, once modal knowledge has been analyzed as consequential upon our constitutive knowledge, and given that there is no particular mystery in how one arrives at the former from the latter, the mysteriousness of modal knowledge is indeed transferred to constitutive knowledge. As a result, most of the action to demystify modal knowledge will be in the as-of-yet-missing epistemology of the constitutive.

Peacocke (2001) starts developing this "urgent task" after being pressed by Heathcote (2001). There, he gives two answers to how we (can) know the Principles. One of them addresses their explicit knowability and the other one their implicit knowability. In what follows, I will argue against these answers that they do not constitute the "attendant epistemology" of the constitutive Peacocke finds urgent. 


\subsection{Explicit knowledge of the Principles}

Peacocke's first answer describes a two-step process that would result in explicit a priori knowledge of the Principles. At the first step of the process, we would identify a set of a priori known modal propositions.

At the second step, we go on to ask 'What is the best explanation of the meaning of necessity that would accord with the truth of these modal propositions that are known a priori?'. I contend that the best explanation is that necessity conforms to the Principles of Possibility. This is an a priori abduction, from a priori data about the truth of certain modal propositions, to a conclusion about the best a priori explanation of why they are true. (Peacocke 2001, 112)

To illustrate this with a one-proposition example, suppose that we identified the a priori known modal proposition that if something is human, it is necessarily human, and let its singleton be the abductive base. By means of the second step, we would abductively arrive at the conclusion that necessity conforms to the principle that if something is human, it is essentially human (plausibly an instance of Essentiality of Kind).

I will argue that this answer is dialectically ineffective. At the first step, Peacocke asks us to identify a set of a priori known modal propositions. Recall, however, that, in Peacocke's account, modal beliefs are given the epistemic status of knowledge to the extent that they inherit it from the epistemic status of the Principles of Possibility. If we had an independent epistemic route to those modal propositions (if we had, for instance, an independent way to know that if something is human, it is necessarily human), that route could be appealed to, at the end of the second step, to support the claim that the principles at which we have abductively arrived are also known (continuing the example: if something is human, it is essentially human). In the absence of independent routes, however, the mere assumption that there is a set of a priori known modal propositions on which to base the abduction will prove ineffective to close the argumentative gap Peacocke wants to close.

Before elaborating on this, let me be clear that I am not objecting to Peacocke's reliance on abductive reasoning as a knowledge-conducive method, or to his assumption about (a priori) modal knowledge. I will only argue for the dialectical ineffectiveness of the particular reasoning he offers. To do so, I will present two cases that should help us to formulate the problem more precisely.

Case One: Let us consider what would be the output of the two-step process in the dramatic event that, constituting our modal concepts, we had only (mindindependent) false implicit beliefs about the constitutive. This implicit conception will have an impact on our modal judgements and, consequently, the abductive base would be constituted by false modal beliefs. By running the two-step process, we would arrive at an explicit formulation of the content of the implicit conception associated to 
our (hypothetically deviant) modal concepts. By assumption-that the implicit conception contains only false statements about the constitutive-plus facticity of knowledge, however, this cannot amount to explicit knowledge of the constitutive principles. It should be granted that, whether we are using deviant or accurate modal concepts, we can run the two-step process. This first case shows that such a process might be a good way to explicitly articulate implicit conceptions. It is not, however, a process that would by itself justify the epistemic status of knowledge ascribed to our beliefs about the constitutive.

Case Two: The implicit conception associated to our modal concepts consists of true implicit beliefs. However, it is by mere epistemic luck that our modal concepts encode the truths of the constitutive realm. In other words, we implicitly possess the truth about the constitutive, but in a way insufficient for knowledge. If modal beliefs inherit their epistemic status from the epistemic status of the implicit conception associated to our modal concepts, then we do not know modal truths; we merely believe them. ${ }^{9}$ These true modal beliefs that we possess can arguably be used as our abductive base to run the two-step process Peacocke describes. As in Case One, however, this might amount to explicit knowledge of what the elements of that implicit conception are, and also to explicit beliefs that those elements state constitutive truths. By assumption, however, it will hardly amount to constitutive knowledge.

One might object that cases One and Two are irrelevant to make a case against Peacocke's first answer since these two cases are ruled out by Peacocke. His abductive base consists of a priori known modal propositions, and this is already incompatible with our two cases above. He then claims that running the two-step abductive process will deliver explicit knowledge of the Principles of Possibility-we arrive at knowledge, because we departed from knowledge.

I agree that this is Peacocke's scenario. Cases One and Two show, nonetheless, that Peacocke's assumption that we have an abductive base with known modal propositions is not dispensable. What we need to evaluate now is whether this abduction-answer constitutes an epistemology of the constitutive adequate to play the role that Peacocke needs it to play: namely, that of completing his epistemology of modality. I shall argue that it does not.

Peacocke is very clear about why he needs an epistemology of the constitutive. To recall, this is how he elucidates modal knowledge:

\begin{tabular}{|c|c|c|}
\hline $\begin{array}{c}\text { Implicit knowledge of } \\
\text { constitutive truths } \\
\text { (IKC) }\end{array}$ & $\rightarrow$ grounds & $\begin{array}{c}\text { Explicit modal knowledge } \\
\text { (EMK) }\end{array}$ \\
\hline
\end{tabular}

\footnotetext{
${ }^{9}$ To see why non-accidentality is important, see Jenkins' similar concerns $(2008 b, 56-65)$ to the effect that accidentality would be knowledge-destroying.
} 
As seen at the beginning of $\S 3$, Peacocke finds this incomplete because, given the epistemic dependence of (EMK) upon (IKC), (IKC) needs to be elucidated too. This is what Peacocke offers now about the explicit knowability of the principles:

\begin{tabular}{|c|c|c|}
\hline $\begin{array}{c}\text { Explicit modal knowledge } \\
(\text { EMK) }\end{array}$ & $\underset{\text { grounds }}{\rightarrow}$ & $\begin{array}{c}\text { Explicit knowledge of } \\
\text { constitutive truths } \\
\text { (EKC) }\end{array}$ \\
\hline
\end{tabular}

Cases One and Two above show the way in which (EKC) depends on (EMK) - that is, how (EKC) depends on modal knowledge as opposed to modal beliefs, whether true or false. According to the only epistemic elucidation of (EMK) we have been given, (EMK) depends, in turn, on (IKC) —we haven't been given any independent route to (EMK). Peacocke's views on the explicit knowability of constitutive truths, therefore, are not suitable to solve the argumentative deficit he identifies. On the contrary, it only expands the explanatory chain in the wrong direction:

\begin{tabular}{|c|c|c|c|c|}
\hline $\begin{array}{c}\text { Implicit knowledge } \\
\text { of } \\
\begin{array}{c}\text { constitutive truths } \\
\text { (IKC) }\end{array}\end{array}$ & grounds & $\begin{array}{c}\text { Explicit modal } \\
\text { knowledge } \\
\text { (EMK) }\end{array}$ & grounds & $\begin{array}{c}\text { Explicit knowledge of } \\
\text { constitutive truths } \\
\text { (EKC) }\end{array}$ \\
\hline
\end{tabular}

If there was an incompleteness problem before-as Peacocke grants and not without good reasons - there is the same incompleteness problem now. Our target question is: How do we know x to be a constitutive truth? Peacocke's answer might be a correct answer to: How can we know the principles explicitly, once we know them implicitly? A correct answer to this second question, however, falls short of what Peacocke needs to complete his modal epistemology.

Before turning to Peacocke's views on the implicit knowability of the principles, let me address an objection someone might raise against my criticism. My reply to this objection will in turn prepare the grounds for my objection (in §3.3) to Peacocke's answer to the problem of the implicit knowability of the principles.

\subsection{Objection and reply}

One might complain that the objection above neglects a crucial aspect of Peacocke's theory on which I will now elaborate. I will explain why, despite the fact that the worry is justified, my criticisms are fair nonetheless. To do so, I will identify an assumption that lies behind the criticism above and show that it is a fair assumption.

What I think is missing in Peacocke's answer is an explanation of why our modal concepts are epistemically felicitous - that is, an explanation of why they correctly and non-accidentally track external, constitutive truth-and, most importantly, an elucidation of the cognitive mechanisms that are responsible for our possessing epistemically felicitous modal concepts. In short, what is missing is an 
epistemological elucidation of our capabilities to know that something is a constitutive truth.

The assumption I need to justify is that, in the context of Peacocke's views, it is legitimate to ask for what I think is missing. Before arguing that it is, let me offer the reasons someone could have to think that it is not. I will do this by elaborating on that crucial aspect of Peacocke's account that my criticism might be said to neglect; and that Peacocke unfolds more explicitly in (Peacocke 2004 and 2008).

Objection: Take the concept <chair>. On Peacocke's theory of concepts, the possession conditions for $<$ chair $>$ are thick enough as to guarantee that the judgement that <this is a chair> as made by <chair>-possessors will typically amount to knowledge that this is a chair (Peacocke 2008, 141). If we think of it in terms of the word 'chair', we can grant that it is a matter of linguistic convention-and therefore contingent - that 'chair' picks up the property of being a chair. If we think of concepts as the lexicon of thought, one could also see some sort of contingency here: it is contingent that we possess the concept $<$ chair $>$. It is crucial to note that this contingency is not enough to make the sentence 'there are chairs' - or the thought $<$ there are chairs $>$-mind-dependently true (e.g., true in virtue of our linguistic conventions or conceptual repertoire). Nominalist worries aside, there is room for mind-independence about chairs. The contingency of which words and concepts we use or have is compatible with facts about which entities fall under those concepts and words being mind-independent. (See (Peacocke 2008, 29 and 151).)

What my criticisms above would be neglecting, according to the current objection, is that Peacocke is offering a theory of modal concepts - and primarily of $<$ possibility >-along the lines of his general theory of concepts:

Possibility is that concept $C$, predicated of specifications, to possess which a thinker must have implicit knowledge of certain principles $P_{1}(C) \ldots P_{n}(C)$, where one of these principles states that any specification falls under $C$ only if any continuant object which exists, according to that specification, has its actual origins. (Peacocke 1999, 147)

Our concept $<$ possibility $>$ is - like that of $<$ chair $>$ - individuated by its possession conditions, and its possession conditions are constituted by the Principles of Possibility, which in turn determine the semantic value of $<$ possibility $>$. As such, possibility-judgements as made by <possibility>-possessors in normal conditions constitute knowledge. One of the principles, according to the above quotation, implies that origins other than the actual ones are impossible. Other principles impose other conditions. All these conditions are conditions on specifications-as it should be, since <possibility> is, as seen in $\S 2$, predicated of specifications. For any specification, $s$, either $s$ satisfies all the conditions imposed, or it does not. If it does, $s$ is possible; if it violates at least one, it is not. So, possibility is that property-referred to by <possibility $>$ - that specifications have in virtue of satisfying all the Principles of Possibility. (To avoid unnecessary confusion, let me make explicit that a 
specification satisfying all Principles of Possibility will be parasitic upon the assignment to which one such specification corresponds satisfying them all too.)

Given Peacocke's metaphysics of $<$ possibility $>$ - the objection would go- there is not much to be said as to how we know possibility facts. Possessing the concept is, as Peacocke contends, enough to know modal facts; and that we possess the concept - together with Peacocke's remarks on the epistemology of modality sketched in $\$ 2$ - should be enough as an explanation of how we know modal facts. Let us compare the following two cases. How do we know that chairs-as opposed to benches or sofas - satisfy the property of being designed to accommodate one person? Because this property is a condition for something to fall under $<$ chair $>$ and knowledge that this is so partially constitutes the possession conditions for $<$ chair $>$. End of story. How do we know that $<$ Madonna has origins different from her actual ones $>$ is impossible? Because it violates one of the conditions for possibility and knowledge of these conditions constitutes the possession conditions for $<$ possibility $>$. End of story.

As in the case of <chair >- the objector would insist - this is compatible with modal truth being mind-independent. There are certain conditions that specifications must satisfy to fall under <possibility>. Whether specifications satisfy those conditions is a mind-independent matter and, therefore, whether something is possible or not is not dependent on what is true about minds in any relevant sense.

Given the nature of $<$ possibility $>$, therefore, the question about the knowability conditions for the principles should have a straightforward answer. They are the principles satisfaction of which is necessary and sufficient to fall under $<$ possibility $>$ and implicit knowledge of which is guaranteed to <possibility $>$-possessors. This crucial aspect of Peacocke's account is nicely stressed and unfolded in (Peacocke 2004, 171-2).

Reply: I distinguish between the truth of what the objection appeals to, and the force of the objection. Truly enough, Peacocke's metaphysics of $\langle$ possibility $>$ is crucial to his strategy to meet the integration challenge. I grant, furthermore, that my objection above might seem to neglect that aspect of his theory. I will argue next that, despite this crucial feature, it is still legitimate to ask about the knowability conditions for the Principles of Possibility.

If the objection is forceful, Peacocke was too concessive $(1999,166)$ in thinking that an epistemology of the constitutive is an urgent task for philosophy. To think so - the argument would go - can only be the consequence of underestimating the nature and power of the account. I believe, however, that Peacocke was not too concessive. My (exegetical) explanation of why he acknowledges the need for an epistemology of the constitutive is that he is aware that - despite his metaphysics of $<$ possibility $>$ _ there are legitimate reasons to ask for it. Let me then elaborate on those reasons. 
We could introduce a number of different concepts in the vicinity of Peacocke's $<$ possibility $>$. For instance, we could introduce $<$ possibility*>, whose constitutive principles (the Principles of Possibility*) are very similar to the Principles of Possibility, except that they imply that Humphrey is possibly* a poached egg, and that two plus two are possibly* five. Arguably, <possibility*> picks up a property, possibility*, and some might find it a very interesting one. There are in fact many properties in the vicinity of possibility and possibility* that one could potentially refer to by means of concepts similar to Peacocke's $<$ possibility $>$, all of which would be individuated by slightly different sets of principles. (With an extensional view on properties, one could argue that there are as many different properties as there are different partitions of $C^{*}$ - the set of all assignments - into two equivalence classes. Presumably, furthermore, nomic possibility, conceptual possibility and logical possibility, each of which characterized by different sets of principles, are amongst them.)

Pre-theoretically, modal concepts track constitutive truth; that is, truths about the nature and identity of things. So thinks Peacocke, reason for which his Principles of Possibility, the ones that individuate $<$ possibility $>$, are said to be principles governing constitutive truth. (Note - in passing though importantly - that the account must accommodate this kind of mind-independence too; and not just the mindindependence that the objector above was insisting upon.) By the assumption above, $<$ possibility $>$ and $<$ possibility* $>$ are not co-extensional. Between them, therefore, only one - at most — correctly tracks constitutive truth. Peacocke thinks $<$ possibility $>$ does. If this is so, it is against Humphrey's nature to be a poached egg. Also, if this is so, we are epistemically very fortunate. We aim at a concept, $C$, that tracks mindindependent constitutive truth, and the concept with which we intend to do so does so. This is a great success, especially because-given the potentially many deviant alternatives - we could easily have failed. We could easily possess instead <possibility*> playing the C-role. Constitutive truth is mind-independent, and this means that there are mind-independent correctness conditions that apply to the implicit conceptions that could potentially play the $C$-role. The implicit conception associated to <possibility*> would be incorrect to play it, because <possibility*> allows* for Humphrey to be a poached egg but this is (assumed to be) against his nature. The possibility of incorrect implicit conceptions is something Peacocke acknowledges (2004, 141-142). Furthermore, in the case of <possibility $>$, and given that the world (and not our minds) fixes constitutive truth, the door is wide open for incorrect implicit conceptions. ${ }^{10}$

10 Relatedly, Wright (2002b) notes that Peacocke-modality might (or might not) be the same (extensionally) as the pre-theoretical modality. He stresses that, for Peacocke's account to succeed, we should recognize that they are the same - if-and-when they are. Wright's complaint — stated in the form of a structural limitation - is that, using Peacocke's concepts, we cannot recognize such a thing: "that apprehension would need to lie-necessarily!-beyond the reach of Peacocke's account" (Wright 2002b, 658). 
It is therefore legitimate to ask how we achieve (in a way sufficient to ground modal knowledge) the correct concept. And this is a legitimate question especially to Peacocke, whose <possibility $>$ is that rich in content. Given his metaphysics of $<$ possibility $>$, his answer to this question will need to provide an explanation of how we are able to discriminate constitutive truth. It is not coincidental that this is the question Peacocke acknowledges we should be in a position to answer if we "do not want all the initial puzzlement about modality simply to be transferred to the domain of the constitutive" $(1999,166)$.

There are then two features of Peacocke's account that - with a view to answering this potential objection-are salient: (i) Peacocke's metaphysics of $<$ possibility $>$; and (ii) that $<$ possibility $>$ tracks mind-independent constitutive truth. My criticisms above exploited at some point - in particular, with Case One- the theoretical possibility that (ii) is false: Maybe <possibility*> is after all the concept that correctly tracks constitutive truth? I did not put much effort there to distinguish the assumption that the Principles of Possibility are false statements about the constitutive, from the assumption that the Principles of Possibility are false statements about the possible. Given (i), however, failure to distinguish these two things could be misleading, if we were using Peacocke's concepts. For note that, given (i), it is absolutely impossible for the Principles of Possibility to be false statements about the possible. To explain why, let me call to the reader's attention that the extensions of 'Principles of Possibility' and 'Constitutive Principles' could come apart. Let me recall also, from $\S 2$, that, according to Peacocke, Essentiality of Kind is a Principle of Possibility. Given this, even if being a poached egg was not against Humphrey's nature-i.e., even if Essentiality of Kind was not a constitutive principle-we could not truly say so using Peacocke's <possibility>. That Humphrey could be a poached egg would remain false, and the Principles of Possibility will remain true principles of the property possibility. Let us suppose that the Constitutive Principles are in fact the Principles of Possibility*. To express the intended truth, we should use the appropriate concepts: Humphrey could* be a poached egg. In other words, if (ii) is false, then, given (i), <possibility $>$ does not refer to the property we intend to refer to by it, but to some other property in the vicinity. If the true mind-independent constitutive principles were instead the Principles of Possibility*, then possibility* would be the property we are after.

The point made above from reflection on cases One and Two might have induced a misinterpretation - as if I was not paying sufficient attention to the distinction between the Principles of Possibility and the Constitutive Principles. The reader can now retrospectively check, however, that I was careful with my choice of words. The point - as it was stated - survives even if we grant Peacocke, for the sake of discussion, (i) and (ii). Cases One and Two were used there to show that (EKC) depends on (EMK). After presenting these cases, I granted that Peacocke's scenario is one in which (ii) is satisfied - and thus one in which the constitutive principles are the Principles of Possibility. When concepts are thought to be as rich as Peacocke 
suggests - i.e., when granting also (i) - , however, how we manage to have the right concept playing the C-role is a legitimate question, especially in the face of the many deviant alternatives. As seen above, Peacocke acknowledges the need for an epistemology of the constitutive. However, he does not make explicit the reasons why this is a legitimate question, and offering those reasons has been the aim of this subsection.

To sum them up: The two-step abductive method yields - and I can grant this because I'm not objecting to abductive reasoning in general - explicit knowledge of the Principles of Possibility. But this will be true whether or not our modal concepts satisfy (ii). So knowledge of (which are) the Principles of Possibility cannot be freely assumed to amount to knowledge of (which are) the Constitutive Principles; and it is the latter we primarily need an epistemological elucidation of.

I complained in $\S 3.1$ that Peacocke's answer about the explicit knowability of the principles only expands the explanatory chain in the wrong direction. An answer to how we manage to non-accidentally possess the right concept is what would expand the explanatory chain in the right direction, but this is missing in Peacocke's remarks explored so far. Let me then turn to Peacocke's answer to the question about the implicit knowability of the principles. The material in this subsection will help us identifying what the main problem with this second answer is.

\subsection{Implicit Knowledge of the Principles}

According to Peacocke

The ordinary understander's tacit knowledge may be acquired in the same way in which any other tacit knowledge that influences judgments, such as tacit knowledge of the definition of 'chair', or of the recursion for addition, may be acquired. Immersion of the learner in sufficiently many examples can generate an underlying state whose content explains the thinker's classification of new examples. When this underlying state has the content of the Principles of Possibility, and has been acquired in ways that rule out other 'nearby' hypothesis about what 'necessarily' means, it will amount to tacit knowledge of the Principles of Possibility. (Peacocke 2001, 112)

On the basis of $\$ 3.2$, we have to distinguish two questions. One is the question of how do we implicitly know the constitutive principles. The other is how do we implicitly know the Principles of Possibility. Failure to carefully distinguish these two questions might lead us astray because, if our <possibility $>$ concept is deviant — and we saw in $\S 3.2$ that the door is wide open for this - one might have knowledge of the Principles of Possibility while lacking any constitutive knowledge (implicit or explicit). With this distinction in mind, let us evaluate Peacocke's answer.

I shall use Case One again, and again for motivational purposes. Suppose then that our <possibility> concept is deviant and, in particular, that the possession conditions for <possibility> are constituted by false statements about the (mind- 
independent) constitutive realm. Immersion might still be effective in this scenario in generating in the learner an underlying state with the content of the implicit conception associated to <possibility $>$. The content of the underlying state in this scenario, however, cannot constitute tacit knowledge of the constitutive since, by hypothesis, this content consists of falsities about the constitutive. We know from $\$ 3.2$ that, given (i) - Peacocke's metaphysics of $<$ possibility $>$ - the principles will still be true Principles of Possibility. However, in this scenario, $<$ possibility $>$ does not refer to the property we are after. Consequently, while_-granting (i)_immersion might generate tacit knowledge of the Principles of Possibility, this would not be targeting the relevant question. The question we should have an answer to is how we implicitly know the constitutive principles.

Similarly to what we saw in $\S 3.1$, one might complain that Case One cannot constitute a case against Peacocke since his starting point is that we have modal knowledge (pre-theoretically understood) and this assumption presumably rules out both the case where we possess deviant modal concepts (Case One) and also the case where we possess the right concept accidentally (Case Two). Let us then grant that $<$ possibility $>$ accurately tracks mind-independent constitutive truth, and that it is no accident that it does so. ${ }^{11}$

It is important to realize, however, that this assumption is only the recognition that there is a phenomenon in need of an explanation; namely, how we have managed to possess (non-accidentally) the right concept. If we could illuminate that, then, immersion might well be a correct answer to how the right concept is transferred to new learners in the linguistic community, who would thereby acquire implicit knowledge of the constitutive principles. That story being absent, however, the answer that appeals to immersion is, at best, incomplete.

Even granting Peacocke his assumption, cases One and Two allow us to realize two things that are important for current purposes. First, even when we might possess the right concept, immersion is not a good way to effectively answer the specific question about the implicit knowability of the constitutive principles. For immersion generates tacit knowledge of the Principles of Possibility whichever property $<$ possibility $>$ refers to. The immersion-answer, therefore, can hardly constitute an answer to the specific question about the cognitive capacities that enable us to discriminate constitutive truth. ${ }^{12}$ Second, the correctness of the immersion-answer depends on us non-accidentally possessing the right concept. On the basis of this dependence, I will next draw a distinction between the correctness and the

11 The problem I will identify in what follows is essentially an instance of the general problem Jenkins identifies in (Jenkins 2008b, 56-65). In her terms, we need an explanation why our concept of $<$ possibility $>$ is, not merely accurate, but grounded.

12 Note, in addition, that, even in the case where we possess the right concept, additional explanatory work might be needed to link our knowledge of the Principles of Possibility (under this intension) to our knowledge of the constitutive principles (under this other intension). Presumably, the cognitive capacity responsible for our non-accidentally possessing the right concept will be indispensably involved here. This also relates to Wright's objection in (Wright 2002b). 
appropriateness of the immersion-answer and argue that, while correct - under the assumption that we non-accidentally possess the right concept - it is not appropriate to close the explanatory gap.

Let me unfold both things simultaneously by means of a comparison to testimony. Peacocke's case can be described as one in which implicit knowledge of the constitutive principles by <possibility>-possessors is transferred to new learners by means of a mechanism - immersion - that can be modelled by analogy to - though not equated with-testimony. In the case of testimony, transfer of knowledge that $p$ requires prior knowledge that $p$. Let $p$ be the proposition that penguins have knees. One way for me to know that $p$ is by being told so by an expert. If I asked about the knowability conditions for $p$, an answer that appeals to deference and testimony in this way might be correct, but is not appropriate. The intended answer should elucidate acquisition of knowledge that $p$ that is independent of prior knowledge that $p$. The comparison with testimony is intended as having heuristic value. Something to be highlighted is that the cognitive capacities involved in our inheriting knowledge that $p$ through testimony need not be the same - and will typically not be the sameas the capacities involved in our acquisition of firsthand knowledge that $p$. (Think of $p$ as Fermat's Theorem; or as the table is red as known through testimony by a blind person.)

I contend that Peacocke's answer suffers, in a similar vein, from lack of appropriateness. The meaning of 'possibility' as reflected in use-by the linguistic behaviour of <possibility >-possessors-will yield tacit knowledge of the constitutive principles as long as <possibility $>$ is non-accidentally the right concept. While the immersion-answer might correctly describe $a$ route to implicit constitutive knowledge, it is not an answer that would allow Peacocke to complete the project of offering a satisfactory epistemology of modality. The answer is silent about the most important thing to this effect: an explanation of how the right concept is nonaccidentally acquired in the first place. For all we have been told, furthermore, and similarly to what happens in the testimony case, inheritors of $<$ possibility $>$ could even lack the relevant capacities which enabled former members of the linguistic community to acquire the right concept in the first place. This is why - as anticipated above - the immersion-answer can hardly constitute an answer to the specific question about the cognitive capacities that enable us to discriminate constitutive truth.

In sum, the story I find missing is, in the context of Peacocke's views, presumably a story about the genesis of the right $<$ possibility $>$. I do not need to speculate about possible stories here. ${ }^{13}$ For current purposes, it suffices to note the explanatory gap.

\footnotetext{
${ }^{13}$ Someone might find attractive the empiricist account Jenkins outlines in her (2008b), although an empiricist route need not be mandatory.
} 


\section{Recap and Preview}

Let me briefly recap what has been developed hitherto and draw the relevant connections with the content of the next section. ${ }^{14}$ So far, I have only argued about an explanatory gap in Peacocke's epistemology of modality. Without closing this gap, the Integration Challenge has not been met. Nothing I have developed so far, however, calls for any modification in Peacocke's account. It could be left as it is and, supplemented with an appropriate epistemology of the constitutive, it could perhaps be said to satisfactorily meet the integration challenge. ${ }^{15}$

I think, however, that an urgent modification is in order. This has to do with Peacocke's metaphysics of <possibility>. As we saw in $\$ 3.2$, the metaphysics of $<$ possibility $>$ is given by the set of Principles of Possibility which in turn constitute its possession conditions. In the next section I will do, roughly, the following. First, I note that Peacocke's possession conditions for <possibility $>$ are (suspiciously) constituted by just the right amount of content that would allow Peacocke to implement his moderate rationalism. Second, I identify three problems around Peacocke's possession conditions for modal concepts: the first two arise from their richness and demandingness and amount to implausibility worries; the third one amounts to a threat that <possibility>, as Peacocke thinks of it, might not be possessable in a way sufficient for modal knowledge. Third, I suggest a modification in the metaphysics of $\langle$ possibility $>$ - and its possession conditions - that avoids those three problems. Forth, I note that, by itself, the resulting account does not meet the Integration Challenge either; it too should be supplemented with an appropriate epistemology.

Nothing developed in this paper, however, suggests that the gap cannot be closed. As far as meeting the challenge is concerned, the next section stresses that Peacocke's account and the modified version are on a par. However, it stresses also that, as far as the possession conditions for modal concepts are concerned, the modified account is less problematic. All things considered, therefore, the modified account is preferable. As we will see, this modified account cannot recycle Peacocke's particular instance of moderate rationalism. This is, in relation to what has been developed so far, the most salient dialectical impact of the next section.

\section{The Rule for < admissible>, and possession conditions}

Peacocke's rule for <admissible $>$ is extensionally given by the Modal Extension Principle (MEP) plus the battery of constitutive principles. In (Roca-Royes 2006), I sketch some alternative rules together with the reasons why Peacocke would not endorse them. Those alternatives are, however, open theoretical options, and an evaluation of their pros and cons is worth making. Here, I will compare Peacocke's

\footnotetext{
${ }^{14}$ Thanks to an anonymous referee for this journal who urged me to spell out these connections.

${ }^{15}$ Although see (Wright 2002b) for reasons for pessimism about it.
} 
rule, (PR), with an alternative one, (ALT). After formulating them, I will argue that: (i) only (PR) is contentful enough to serve Peacocke's strategy; (ii) since the challenge has not been met (if the arguments in $\S 3$ are correct), the replacement of (PR) with (ALT) would involve no extra loss; (iii) endorsement of (PR) is problematic in a way that (ALT) is not. Given (i)-(iii), (ALT) should be preferred.

Let me start by formulating the rules. (PR) can be schematized as follows: An assignment $s$ is admissible iff:

- For any concept $C$, the semantic value of $C$ according to $s$ is the result of applying the same rule as is applied in the determination of the actual semantic value of $C$. (This is the condition imposed by MEP.); and

- Constitutive Principle-1; and

- Constitutive Principle-2; and

- Constitutive Principle-3; etc.

(PR) lists all constitutive principles one by one. There is an asymmetry in the way (PR) treats constitutive facts about concepts and constitutive facts about entities at the level of reference. Whereas it rules all constitutive facts about concepts with one single principle, MEP, no analogous single principle rules all constitutive facts about the entities at the level of reference. A principle that would do so, in a way analogous to MEP, would be along the following lines: ${ }^{16}$

(Const) An assignment $s$ is admissible only if, for any entities $e_{1} \ldots e_{n}$ (objects, properties or relations) and for any n-ary relation $R, \mathrm{n} \geq 1$, such that entities $e_{1} \ldots e_{n}$ constitutively stand in the relation $R, s$ does not count $R e_{1} \ldots e_{n}$ as false.

Using (Const), we can formulate the alternative rule for $<$ admissible $>,($ ALT $):{ }^{17}$

(ALT) An assignment $s$ is admissible iff

- For any concept $C$, the semantic value of $C$ according to $S$ is the result of applying the same rule as is applied in the determination of the actual semantic value of $C$. (This is the condition imposed by MEP.); and

16 For (Const) to be perfectly analogous to MEP, we may add that $R$ holds "in the actual world". This would straightforwardly give us S4. However, this would assume that constitutive facts are absolutely necessary of the objects. Although this may have strong intuitive appeal, it is desirable to offer a formulation that is neutral about it, even if Peacocke is not always neutral (see (Peacocke 1999, 147)). Peacocke is aware that the way he formulates MEP lacks this neutrality, and justifies the corresponding assumption (Peacocke 1999, 148-9 and 152-3) that constitutive facts about concepts are necessarily so.

17 It is due to Constrained Recombination that we can formulate both (ALT) and (PR) in biconditional terms. 
- $\quad$ For any entities $e_{1} \ldots \mathrm{e}_{\mathrm{n}}$ (objects, properties or relations) and for any n-ary relation $R, \mathrm{n} \geq 1$, such that entities $e_{1} \ldots e_{n}$ constitutively stand in the relation $R, s$ does not count $R e_{1} \ldots e_{n}$ as false. (This is the condition imposed by (Const).)

The difference in symmetry between (PR) and (ALT) is relevant to argue for claim (i) of this section. The implicit conception associated with the concept $<$ possibility $>$ takes its material from the rule for $<$ admissible $>$. Given the content of (PR), such implicit conception includes all Principles of Possibility. To non-accidentally possess the right <possibility>, therefore, one must implicitly know all the constitutive principles; it wouldn't be enough to know a general principle along the lines of (Const). The implementation of Peacocke's moderate rationalism requires (PR). For it is because of (PR)'s richness in content that possession of modal concepts can guide modal judgement in the way Peacocke suggests. When evaluating whether, for a certain entity, e, 'possibly $\mathrm{p}(e)$ ' holds, any subject who possesses Peacocke's $<$ possibility $>$ has available implicit knowledge as to whether $e$ 's constitutive facts allow for $e$ 's satisfaction of $\mathrm{p}(\mathrm{x})$. It is this implicit knowledge that guides the subject's judgement that 'possibly $\mathrm{p}(e)$ ' is true-when it is. (ALT), by contrast, cannot explain modal judgement in this way. If the possession conditions for $<$ possibility $>$ were determined by (ALT), the implicit knowledge that a subject would have in virtue of possessing this concept would be insufficient to unconditionally judge whether 'Possibly $\mathrm{p}(e)$ ' holds. The farthest this subject would get by deploying the implicit conception that (ALT) provides would be this:

Possibly, $\mathrm{p}(e)$, if $e$ 's constitutive facts allow for $e^{\prime}$ s satisfaction of $\mathrm{p}(\mathrm{x})$.

In order for this subject to be able to discharge the antecedent, she would have to know $e$ 's constitutive facts independently. Possession of (ALT)-<possibility $>$ is certainly not informative enough for (unconditional) modal judgement and, consequently, it is insufficient for modal knowledge. Therefore, Peacocke cannot allow (ALT) to be the rule for $<$ admissible $>$ because it is not contentful enough for his moderate rationalism to have a chance to succeed.

To complete the argument for (i), I will now argue that (PR) is contentful enough by addressing a worry that it might not be. We noted above that (PR) treats constitutive facts about concepts and constitutive facts about entities at the level of reference asymmetrically. It is precisely due to the fact that (PR) lists all the constitutive principles, that $<$ possibility $>$-possessors can unconditionally judge de re possibilities without antecedently possessing constitutive knowledge beyond that which is guaranteed by the possession of $<$ possibility $>$ : (PR) encodes all constitutive facts the subject needs to know in order to discharge the antecedent. By contrast, (PR) does not enable the subject to unconditionally judge de dicto possibilities. One could worry, therefore, that this threatens Peacocke's moderate rationalism. I will argue next that, while there is something right in this worry, it is not particularly pressing. 
Given the content of MEP and the lack of specific conceptual principles, it is true that, in the conceptual case, possession of $<$ possibility $>$ will only allow us to get this far in our judgement:

Possibly, there are unmarried bachelors if the rules governing the concepts unmarried and bachelor allow for their coherent co-applicability.

As above, in order to be able to discharge the antecedent, the subject must have independent knowledge about the rules governing the concepts unmarried and bachelor. Possession of <possibility> plus our independent knowledge of those rules would give us all we need to unconditionally reach de dicto modal judgements. I contend, however, that the asymmetry of (PR) does not seriously threaten Peacocke's strategy because an adequate epistemology for constitutive facts about concepts appears to be available - and the phenomenon of conceptual knowledge less puzzling. This contrasts with the de re case.

This concludes the reasons for (i). To summarize them, (PR) provides the minimum amount of content that allows Peacocke to implement his strategy. (ALT) provides less than that, and a third hypothetical rule that would replace (MEP) with a battery of specific constitutive principles for concepts would be richer than needed. Of the two rules considered here, therefore, only (PR) has a chance to serve Peacocke's moderate rationalism.

In $\S 3$, I argued that the challenge has not been met. If those arguments are correct, and if I am right that the main reasons for preferring (PR) to (ALT) have to do with epistemological concerns, then, we seem to have enough reasons for claim (ii) above - that no extra explanatory power would be lost if we replaced (PR) with (ALT). For despite the account's endorsement of the richer (PR), an epistemology of the constitutive is nonetheless missing in the account. Consequently, the extra content in (PR) is not, against what might have been intended, helping to meet the integration challenge. As anticipated by (iii), furthermore, there are reasons to prefer (ALT) to (PR) which have to do with the different possession conditions for modal concepts that these two rules imply. Let me now elaborate on them.

The first worry concerning (PR) comes from its richness in content. (PR) encodes a whole theory about the (mind-independent) constitutive realm. One might then complain that the possession conditions for <possibility> are, as a result, highly controversial and arguably too demanding. Peacocke's claim that "someone who understands modal discourse has a form of implicit knowledge of the Principles of Possibility" (1999, 125) would be hardly problematic if those principles only said what (MEP) and (Const) say: namely, that metaphysical modality is a matter of what is allowed by constitutive facts. It is more controversial, however, when the Principles already say what these facts are. 
A second worry-somehow related to the first-arises from modal disagreement. On Peacocke's account, when two subjects disagree about some modal fact, at least one of them either is making a mistake - not being appropriately employing the implicit knowledge of the principles that she has in virtue of possessing the concepts - or does not possess modal concepts. I find this explanation wanting. First, against the second disjunct, modal disagreements are frequent among sophisticated modal philosophers of whom it would be implausible to claim that they do not possess modal concepts. Second, against the first disjunct, implicit knowledge of the principles, even though implicit, is assumed to be quite close to the personal level (Peacocke 1999, 164). This suggests that it should not be particularly difficult for sophisticated thinkers who possess modal concepts to appropriately employ this implicit knowledge in reaching modal judgements. ${ }^{18}$

The final reason why (ALT) is preferable requires a bit more interpretation; we need to look at the consequences of what Peacocke writes in different places. First, as just mentioned, Peacocke claims that

Implicit knowledge of the Principles of Possibility seems to be rather closer to the operations of reason at the personal level than is the classic Chomskian case of tacit knowledge of the principles of grammar of our natural language. (Peacocke 1999, 164)

Second, once we implicitly know these Principles, there would be a fairly simple twostep abductive process that would result in explicit knowledge of them. Finally, Peacocke adds to this that we are not guaranteed that all the principles are knowable:

There is no obvious reason that we should be able to know the constitutive properties and relations of each item in our ontology. It takes hard philosophical investigation to discover them, and we may be intellectually limited in our ability to attain knowledge of them. (Peacocke 1999, 166; my emphasis)

It is not obvious whether it is implicit or explicit unknowability that Peacocke is thinking of here. He might be suggesting that we might not be able to explicitly know all the Constitutive Principles, compatibly with us nonetheless knowing them all implicitly by virtue of possessing < possibility $>$. I shall argue, however, that whatever reasons there are to think that some principles might be explicitly unknowable are also reasons to support - in his account - their implicit unknowability too. First, it will be at least odd to say that, in virtue of possessing modal concepts, we know all the principles implicitly but might be "intellectually limited" to know them explicitly. Second, when implicit knowledge of these principles is as close to the personal level as Peacocke suggests, and when it is relatively easy-by means of the two-step abductive process - to make them explicit, it would be odd also to claim that $<$ possibility>-possessors know all the principles implicitly but might not be able to know (some of) them explicitly. Third, if Peacocke's suggestion was that all the

18 Thanks to an anonymous referee for this journal for calling my attention to this. 
principles are implicitly known, while some might not be explicitly knowable, the task would remain for him to tell us how the abductive method he describes, which would lead us to explicit knowledge of the principles, could allow us to know only some of them. This appears to be particularly difficult. For, if we implicitly know all the Principles, and given the proximity to the personal level, nothing should prevent us from being able to use an abductive base strong enough to support the explicit articulation of all of them. ${ }^{19}$

If some constitutive principles might be unknowable even implicitly, then, endorsing (PR) commits us to the claim that we might not be able to possess $<$ possibility $>$ in a grounded ${ }^{20}$ way-i.e., in a way sufficient for modal knowledge. I shall call this "the (grounded) unpossessability threat". ${ }^{21}$ The problem arises because Peacocke seems to value - as a desideratum — that his theory leaves room for partial modal scepticism. This desideratum, however, is in tension with his moderate rationalism. For, as we have seen above, Peacocke's particular kind of moderate rationalism depends on the rule for $<$ admissible $>$ being (PR), and (PR) requires implicit knowledge — and therefore knowability — of all the Principles of Possibility. ${ }^{22}$

A hint on how to escape this tension without renouncing the desideratum can be found in what follows. Peacocke suggests that also some conceptual constitutive facts might be unknowable:

There is no obvious guarantee that everything which is constitutively involved in possession of a particular concept, even one of our concepts, must be discoverable by us. (Peacocke 1999, 166)

This kind of potential unknowability, however, and due to (PR)'s asymmetry, does not threaten the (grounded) possessability of $<$ possibility $>$. For even when we may not know that $R$ is the constitutive rule of a given concept $C$, we may still know MEP (the only Principle of Possibility at the level of concepts), which only requires us to know the conditional that: if $R$ is the constitutive rule of $C$, then any admissible assignment determines the semantic value of $C$ by applying rule $R$. Compatibly with non-accidentally possessing Peacocke's $<$ possibility $>$, therefore, we may know this conditional without knowing whether the antecedent is true or false.

After this hint, a way of avoiding the tension presents itself: (ALT) avoids the (grounded) unpossessability threat at both the conceptual and the de re levels. If the

19 Thanks to an anonymous referee for this journal for pressing me to clarify this.

20 I'm borrowing Jenkins terminology in (2008b).

21 To be clear, we could still accidentally possess the right concept-i.e., we could still be in Case Two. Yet, if it is an accident that we possess it, Peacocke's claim $(1999,162)$ that modal judgment reached by appropriately employing modal concepts can count as knowledge should lose all its plausibility.

22 Given that this implicit knowledge is supposed to guide modal judgement in a way sufficient for knowledge, it is difficult to combine the claim that we have implicit knowledge of all of them with partial modal scepticism. To this effect, a potential distinction between principles that guide and principles that cannot guide modal judgement should not only be made but it should also be made plausible. Nothing like this, however, has even been suggested by Peacocke. 
possession conditions for < possibility > were given by the conjunction of both MEP and (Const), the unknowability of particular de re constitutive principles would have, for analogous reasons, no negative effect on the grounded possessability of $<$ possibility $>$. Importantly, this way of avoiding this tension also avoids the first two (implausibility) worries. This concludes my argument for (iii).

With (i)-(iii) in place, therefore, the (ALT)-account should be acknowledged as preferable. This modified account does not allow us to reach unconditionalized modal judgements in the way Peacocke thinks we reach it. It cannot, therefore, support Peacocke's moderate rationalism.

\section{§6. Concluding remarks and prospects}

In $\S 5$, I argued that (PR) encodes the minimum amount of content needed to implement Peacocke's moderate rationalism. This content, however, even though minimal in this sense, exceeds what could plausibly constitute the possession conditions for modal concepts, and this gave us a reason to prefer (ALT) instead. Furthermore, when those possession conditions are said to include a whole theory of the (mind-independent) constitutive realm, and when we are not guaranteed to have full epistemic access to such realm, the worry arises that we are not guaranteed to be able to non-accidentally possess <possibility>. The fact that (ALT) avoids this problem too gave us a further reason to prefer it.

If we endorse (ALT), we still will need to develop an epistemology of modality. For (ALT) only requires of $<$ possibility $>$-possessors that they know that possibility is a matter of what is allowed by constitutive truths, while remaining silent about which these are. However, $\S 3$ argues that even endorsing (PR), we are also missing a satisfactory epistemology of modality. All things considered, therefore, there is no need to endorse Peacocke's highly demanding possession conditions for $<$ possibility $>$.

A residual - though nonetheless important-question is whether an epistemology of the constitutive is forthcoming. This is not the place for me to say anything positive about it. Instead, I will only identify one further difference between Peacocke's account and the modified one. The difference has to do with how under pressure these accounts are to offer an epistemology of the constitutive.

It should be clear by now that, given Peacocke's metaphysics of $<$ possibility $>$, he is under pressure to offer an epistemology of the constitutive principles. Things are otherwise for the modified account. According to it, possession of modal concepts allows us to know only conditionals of the sort:

Possibly, $p(e)$, if $e$ 's constitutive facts allow for $e$ 's satisfaction of $\mathrm{p}(\mathrm{x})$.

There are two things to be noted here. First, as far as the metaphysics of $<$ possibility $>$ is concerned, this account is not committed to any unconditionalized modal knowledge. Because of this, the modified account is compatible with radical modal 
agnosticism or scepticism. Consequently, all pressure that an (ALT)-account will be under to offer an epistemology of the constitutive will result from the accounts' explicit commitments regarding the knowability of modal truth that will need to be added as independent premises. Second, even when some modal truths were claimed to be knowable, the account-unlike Peacocke's - is not committed to the knowability of all-if-some; so it is compatible also with different degrees of partial modal agnosticism or scepticism. For, unlike Peacocke's, the (skeleton of the) modified account is silent on whether it is the antecedent or the consequent of the conditional above that has epistemic priority. ${ }^{23}$ We might know that $e$ 's constitutive facts allow for $e$ 's satisfaction of $\mathrm{p}(\mathrm{x})$ on the basis of prior knowledge of what those constitutive facts are. Alternatively, we might know first that possibly, $p(e)$, thereby being in a position to know that, whatever facts are constitutive of $e$, they allow for $e$ 's satisfaction of $\mathrm{p}(\mathrm{x})$. In this latter case, we might possess a great deal of possibility knowledge without being in a position to infer any constitutive principle. ${ }^{24}$ There is room here for agnosticism or scepticism about all the constitutive principles without it amounting to agnosticism or scepticism about all possibility-facts.

It would be wrong to think, therefore, that a satisfactory epistemology of modality will always depend on a satisfactory epistemology of the constitutive. The modified account is very versatile about the kind of epistemology of modality it can be made compatible with. It has not met the integration challenge, but this is not to say that the challenge cannot be met somehow, and it leaves room for many different ways to meet it. It does exclude, however, Peacocke's moderate rationalism. ${ }^{*}$

\section{REFERENCES}

Bealer, G. 1999. A Theory of the A Priori. Philosophical Perspectives, 13: 29-55.

\footnotetext{
${ }^{23}$ I might have suggested otherwise in $\S 5$, when I wrote that "In order for [the] subject to be able to discharge the antecedent, she would have to know $e$ 's constitutive facts independently". This is an over-statement. However, it was convenient there for the sake of exposition, and dialectically permitted because the relevant comparison in $\S 5$ was between the different routes to possibility knowledge from constitutive knowledge that (PR) and (ALT) can offer. What I am stressing now is that, unlike Peacocke's moderate rationalism, (ALT) is not committed to this being our route to possibilityknowledge.

${ }^{24}$ For more on the distinction I have in mind here, see (Hale 2002) and (Roca-Royes 2007).

* Thanks to Ross Cameron, Fabrice Correia, Manuel García-Carpintero, Bob Hale, Jonathan Ichikawa, Carrie Jenkins, Dan López de Sa, Chris Peacocke, Luís Robledo, Sven Rosenkranz, Crispin Wright, and Elia Zardini. Thanks also to the audience at the NIP Basic Knowledge Seminar (Aberdeen) with whom I had the chance to discuss a late version of the paper; and also to the audiences of the II Arché Graduate Conference (St. Andrews) and the Fifth European Conference for Analytic Philosophy (Lisbon), where I presented older drafts. I'm also extremely grateful to the several anonymous referees for this journal, whose penetrating comments (which certainly went beyond the call of duty) have allowed me to considerably improve the paper. The paper was written in part with financial support from the project HUM2006-09923 (MEC). Thanks also to Mike Maudsley for his linguistic corrections.
} 
BEALER, G. 2002. Modal epistemology and the rationalist renaissance. In Conceivability and Possibility, ed. T.Gendler and J. Hawthorne. Oxford: Clarendon Press.

BENACERRAF, P. 1973. Mathematical Truth. Journal of Philosophy 70: 661-679.

BlackBuRn, S. 1986 \& 1993. Morals and modals. In Essays in Quasi-Realism, 52-74. Oxford: OUP.

BRUECKNER, A. 2001. Chalmers's conceivability argument for dualism. Analysis 61: 187-193.

Chalmers, D. 2002. Does conceivability entail possibility? In Conceivability and Possibility, ed. T. Gendler and J. Hawthorne, 145-200. Oxford: Clarendon Press.

Craig, E. 1985. Arithmetic and fact. In Essays in Analysis, ed I. Hacking, 89-112. Cambridge: CUP.

FINE, K. 1994. Essence and modality. Philosophical Perspectives, 8, Logic and Language: $1-16$.

Jenkins, C. 2005. Realism and Independence. American Philosophical Quarterly, 42/3: 199-211.

JENKIns, C. 2008a. Modal Knowledge, Counterfactual Knowledge and the Role of Experience. Philosophical Quarterly, 88 (233), 693-701.

JenkIns, C. 2008b. Grounding Concepts. An Empirical Basis for Arithmetical Knowledge. Oxford: Oxford University Press.

Hale, B. 2003. Knowledge of Possibility and of Necessity. Proceedings of the Aristotelian Society, CIII, 1-20.

Heathcote, A. 2001. Yes, but what is the mother of necessity? Philosophical Books, cc42(2): 92-100.

HILL, C. 2006. Modality, Modal Epistemology, and the Metaphysics of Consciousness. In S. Nichols (Ed.), The Architecture of Imagination (pp. 205-236). Oxford University Press.

KMENT, B. 2006. Counterfactuals and the Analysis of Necessity. Philosophical Perspectives 20: 237-302.

KRIPKE, S. 1980. Naming and Necessity. Cambridge, Massachusetts: Harvard University Press.

LEWIS, D. 1986. On the Plurality of Worlds, Oxford: Basil Blackwell.

Lowe, J. 2007. A Problem for A Posteriori Essentialism Concerning Natural Kinds. Analysis 67: 286-292

MenZIES, P. 1998. Possibility and Conceivability: A Response-Dependent Account of Their Connections. In R. Casati (Ed.), European Review of Philosophy, 3: 255-277.

Nolan, D. 1997. Impossible Worlds: a modest approach. Notre Dame Journal of Formal Logic, 38, 535-72.

PeACOCKE, C. 1999. Being Known. Oxford: Oxford University Press. 
PeAcocke, C. 2001. The past, necessity, externalism and entitlement. Philosophical Books, 42(2): 106-117.

Peacocke, C. 2002. Principles for Possibilia. Noûs, 36:3, 486-508.

PeAcocke, C. 2004. The realm of reason. Oxford: Oxford University Press.

PeAcocke, C. 2008. Truly Understood. Oxford: Oxford University Press.

Putnam, H. 1975. The Meaning of 'Meaning', in Mind, Language, and Reality, Cambridge University Press, Cambridge. Van Inwagen, P. 1998. Modal Epistemology. Philosophical Studies 92: 67-84.

RocA-Royes, S. 2006. Peacocke's Principle-Based Account of Modality: "Flexibility of Origins" Plus S4. Erkenntnis, 65/3: 405-26.

RocA-Royes, S. 2007. Mind-Independence and Modal Empiricism. Proceedings of the $4^{\text {th }}$ Latin Meeting for Analytic Philosophy (Genoa), 117-135.

RocA-Royes, S. forthcominga. Conceivability and De Re Modal Knowledge. Noûs.

RocA-Royes, S. forthcomingb. Modal Knowledge and Counterfactual Knowledge. Logique et Analyse.

VAIDYA, A. 2007. The epistemology of modality. Stanford Encyclopedia of Philosophy.

Van Inwagen, P. 1998. Modal Epistemology. Philosophical Studies, vol.92: 67-84.

Williamson, T. 2007. The Philosophy of Philosophy. Blackwell Publishing.

Worley, S. 2003. Conceivability, possibility and physicalism. Analysis 63: 15-23.

Wright, C. 2002a. The Conceivability of Naturalism. In Conceivability and Possibility, ed. T. Gendler and J. Hawthorne. Oxford: Clarendon Press.

Wright, C. 2002b. On Knowing What is Necessary: Three Limitations of Peacocke's Account. Philosophy and Phenomenological Research, LXIV(3), 655-662.

YABLO, S. 1993. Is Conceivability a Guide to Possibility? Philosophy and Phenomenological Research, 53:1-42. 